\title{
The influence of social stigmas on observers' eye movements
}

\author{
Frouke Hermens \\ University of Lincoln, UK
}

\begin{abstract}
Some social stigmas (facial scars, tattoos) have clear visual cues and eye tracking has shown that such social stigmas influence the eye movements of other people. Other social stigmas (e.g., a mental illness or a criminal record) often lack clear visible cues. The present study investigates whether providing information about such stigmas draws eye movements of observers to the people involved. Participants were presented with video clips and advance information about one of the actors that was either stigmatizing (related to mental health or a criminal past) or non-stigmatizing. The results show that eye movements towards the target actor were not systematically affected by stigmatizing advance information and were not associated with explicit attitudes from questionnaires. Results therefore suggest that stigmas without clear visual cues do not draw attention to or away from the person involved.
\end{abstract}

Keywords: social stigma, eye movements, attitudes.

Some social stigmas have clear visual cues, such as those associated with facial scars, tattoos, a cleft lip, and obesity. Eye tracking studies have shown that these stigmas influence how observers look at the person with the stigma (Madera \& Hebl, 2012; Meyer-Marcotty, Gerdes, Reuther, StellzigEisenhauer, \& Alpers, 2010; Van Schijndel, Litschel, Maal, Bergé, \& Tasman, 2015; Wohlrab, Fink, Pyritz, Rahlfs, \& Kappeler, 2007). For example, it has been found that observers more strongly focus on the mouth region when looking at photographs of individuals with a cleft lip and nose (Meyer-Marcotty et al., 2010; Van Schijndel et al., 2015). Likewise, more pronounced visual attention was found towards scars (Madera \& Hebl, 2012) and tattoos (Wohlrab et al., 2007). Other social stigmas often leave less obvious visual cues, and therefore rely on information given to the observer. For example, mental health conditions or a criminal past do not always leave visual cues, but can lead to a strong social stigma (Barney, Griffiths, Jorm, \& Christensen, 2006; Conner et al., 2010; Driscoll, Heary, Hennessy, \& McKeague, 2012; Eisenberg, Downs, Golberstein, \& Zivin, 2009; Komiti, Judd, \& Jackson, 2006; Nadeem et al., 2007; Pager, 2003; Reynders, Kerkhof, Molenberghs, \& Van Audenhove, 2014; Schomerus, Matschinger, \& Angermeyer, 2009; Schwartz \& Skolnick, 1962). The stigma involved with such conditions, however, may prevent people from discussing their condition or seeking help (Barney et al., 2006; Conner et al., 2010; Nadeem et al., 2007; Reynders et al., 2014; Schomerus et al., 2009). While studies have demonstrated that visible stigmas influence other people's eye movements towards the person involved (Madera

The author greatly acknowledges the help from Amber Hawes and Ebony Cundy with stimulus selection, participant recruitment and testing. This paper has been accepted for publication in the Journal of Articles in Support of the Null Hypothesis (JASNH).
\& Hebl, 2012; Meyer-Marcotty et al., 2010; Van Schijndel et al., 2015; Wohlrab et al., 2007), no study to date has examined whether revealing a person's mental illness or criminal past influences other people's gaze. The present study aims to do so.

The general setup by Van Schijndel et al. (2015) was employed, but instead of static images, videos were used to increase the ecological validity of the stimuli. Participants were shown several movie clips. Before each video, they saw an information screen that revealed something about one of the actors in the video. This information could be about a mental condition (Experiment 1), a criminal past (Experiment 2), or be of a non-stigmatizing nature (e.g., the actor had just returned from a long distance trip; serving as a baseline). After the video clips, participants also completed a questionnaire about their attitudes towards mental health (Experiment 1) or prisoners (Experiment 2). The scores on these questionnaires were compared to the eye movement patterns to examine whether individuals with high scores on the scales showed different eye movement patterns compared to participants with low scores.

If eye movements can be shown to be systematically influenced by stigmatizing information, this could provide a new method to examine implicit attitudes towards such stigmas. The study of attitudes often relies on questionnaires (e.g., the attitudes towards prisoners scale, Kjelsberg, Skoglund, \& Rustad, 2007; Melvin, Gramling, \& Gardner, 1985), which can suffer from a social desirability bias (Hebert, Clemow, Pbert, Ockene, \& Ockene, 1995; Mortel et al., 2008; Nederhof, 1985). Alternatively, reaction time measures are used, such as in the implicit association test (IAT, Greenwald, McGhee, \& Schwartz, 1998), but these have been criticized for measuring associations rather than attitudes (Fiedler, Messner, \& Bluemke, 2006; De Houwer, 2002), and often depend on the ability to read words quickly.

Based on past studies examining eye movements towards social stigmas (Madera \& Hebl, 2012; Meyer-Marcotty et al., 
2010; Van Schijndel et al., 2015; Wohlrab et al., 2007), it is predicted that eye movements are drawn towards the actor when stigmatizing information is given. It is also predicted that individuals will fixate the target actor more quickly, as past studies on spider phobia (Gerdes, Pauli, \& Alpers, 2009; Miltner, Krieschel, Hecht, Trippe, \& Weiss, 2004; Rinck \& Becker, 2006) have suggested that feared items draw attention reflexively. These studies have also suggested that after the initial reflexive gaze shift towards the feared object, people look away from the object. It may therefore be the case that observers first fixate the actor's face, but then avoid direct eye contact and look at the body instead. To examine this possibility, the relative time spent fixating the face was therefore also measured.

\section{Experiment 1}

Experiment 1 examined the influence of information about an actor's mental illness on observers' eye movements.

\section{Methods}

Participants. Thirty-four participants took part in the study (almost all female, between 19 and 36 years of age), recruited from the University of Lincoln by word of mouth and an online recruitment system. Participants were reimbursed with course credit or candy. All provided written consent for their participation in the study that was approved by the local ethics committee and conducted in agreement with guidelines of the British Psychological Society (BPS) and the declaration of Helsinki.

\section{Apparatus.}

Stimuli were presented on a flat screen monitor (Viewsonic VX2268 WM), set at a resolution of 1024 by 768 pixels and a refresh rate of $60 \mathrm{~Hz}$ and positioned at a distance of $77 \mathrm{~cm}$ from the chin-and-forehead rest used to stabilize participants' heads to improve accuracy of the eye movement recordings. Stimuli were presented using the Experiment Builder software (SR Research, ON, Canada). Eye movements were recorded using the Eyelink 1000 system (SR Research, ON, Canada). Eye tracking was performed monocularly in the left eye (the eye that was easiest to track with the right-positioned IR illuminator ${ }^{1}$ ). Eye movements were sampled at $1000 \mathrm{~Hz}$ and automatically parsed into fixations and saccades using the Eyelink's parsing software, using the default thresholds for velocity $(30 \mathrm{deg} / \mathrm{sec})$ and acceleration $\left(9,500 \mathrm{deg} / \mathrm{sec}^{2}\right)$. Participants responded to the questions about the movie clips and the questionnaires using a standard computer mouse.

\section{Stimuli.}

Figure 1 shows the stimulus sequence. Participants were first presented with a description of one of the actors in the upcoming video clip together with an image of this actor. The information was presented for $5000 \mathrm{~ms}$, followed by a short blank (300ms), and the movie clip (lasting between 10 and 20 seconds). After another short blank screen (400ms), a question was presented about the video clip to encourage participants to pay attention to the videos. Participants responded to these questions by clicking with the mouse on the answer (multiple choice). Video clips were 20 short extracts from YouTube videos and showed a range of day-today scenes, including work situations, social events, and interactions between people. A description of the video clips and the information provided with each video clip is provided in Table 4 . Videos were scaled back to a size of 640 by 480 pixels (30 frames per second) and presented in the center of the display without the original sound.

After the eye tracking session, participants were given a short questionnaire to probe into their explicit attitudes towards ill mental health, including questions about whether they accept certain mental illnesses in certain professions, whether they personally had experience with people with mental illnesses, and what their attitudes were towards the rights of people with mental illnesses. For the present purpose, only the questions regarding mental illness in professions were analyzed, of which an overview is provided in Table 1. The questionnaire was presented on the same computer as the video clips, but eye movements were no longer tracked. Questions were presented one by one and participants responded by clicking with the mouse on their desired response.

\section{Design.}

The two types of information (neutral or stigmatizing) were counter-balanced across participants. Participants each received mental health information in half of the video clips and neutral information in the other half. The order of the video clips was randomized for each participant. Participants all completed the eye tracking part of the study before completing the questionnaire. The questions in the questionnaire were presented in the same order to all participants.

\section{Procedure.}

Participants were tested individually. After receiving written and verbal instructions and signing a consent form, participants took place in the head-and-chin rest positioned in front of the computer screen. Before they were shown the videos, the eye tracker was calibrated. This calibration procedure involved participants fixating a series of ten dots placed on a rectangular three by three grid on the computer screen. Calibration was considered successful if the recorded gaze positions were aligned to the three by three grid used for the calibration targets (resulting in a reported $0.25^{\circ}$ deg to $0.5^{\circ}$ accuracy and $0.01^{\circ}$ RMS spatial resolution, SR Research, ON, Canada). Participants were then presented with the sequences of advance information, video clips and questions (Figure 1) and were asked to respond to the questions by clicking with the computer mouse on the answer they thought was correct. After completing the eye tracking session, participants completed a short questionnaire about

\footnotetext{
${ }^{1}$ While studies have suggested eye tracking accuracy to be less in the (often left) non-dominant eye (Nyström, Andersson, Holmqvist, \& Van De Weijer, 2013), the reported difference between the dominant and non-dominant eye is small, particularly in comparison to the size of the regions of interest used here.
} 
a) Stimulus sequence

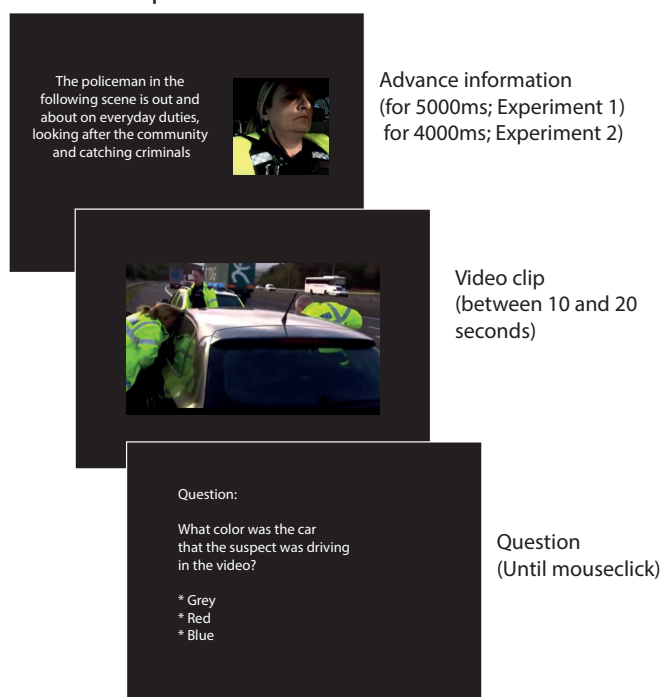

b) Regions of interest analysis

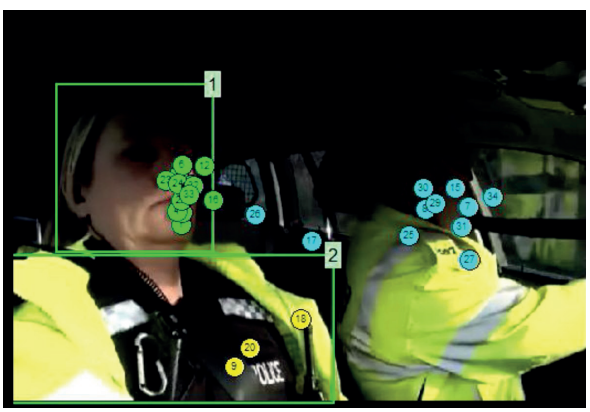

Figure 1. a) Stimulus sequence. A preview was shown with an image of the target actor and either neutral information or possibly stigmatizing information for 5000ms (Experiment 1) or for $4000 \mathrm{~ms}$ (Experiment 2). After a short blank for 300ms (not shown), this preview was followed by a short video clip containing the target actor, another short blank for 400ms (not shown) and a question to encourage participants to pay attention. b) Illustration of the analysis of the eye movement analysis. Regions of interest were drawn around the target actor's head and body (rectangles), and fixations (filled numbered circles, one for each participant) were classified as being directed towards these regions or elsewhere on the screen. Regions of interest were created for each frame of the video.

\section{Table 1}

Questions and results (percentage of participants clicking the 'yes' button) from the questionnaire in Experiment 1. The responses for each participant were combined into a single score indicating how open the participant was to mental health disorders in professions overall, with questions weighted on the basis of what percentage of participants thought the condition was acceptable.

\begin{tabular}{l} 
Question \\
Would you feel safe flying, knowing that the pilot suffered from self-harm? \\
Would you be influenced by a model in the new season's catwalk to buy clothing, even if they were suffering from an eating disorder? \\
Would you trust a policeman within your community, even they are suffering from the mental health disorder schizophrenia? \\
Would you allow a teacher to teach your child within a school environment, even if they are suffering from depression? \\
Would you trust a nurse with diagnosis, even if they were suffering from an anxiety disorder? \\
Would you feel comfortable having advice from a counselor, even if they were suffering from hallucinations? \\
Would you feel comfortable having a babysitter for your child, knowing that the babysitter suffered from Post-traumatic stress disorder? \\
Would you feel comfortable knowing that one of your grandparents is being cared for by a carer who suffers from paranoia? \\
Would you feel comfortable getting in a taxi home after a night out, knowing that the taxi driver suffers from a Personality disorder? \\
\hline
\end{tabular}

their attitudes towards mental illnesses presented as individual slides on the same computer screen, and again the mouse was used to indicate the response. Before leaving, participants were debriefed, and were informed that all information about the actors was completely fictional.

\section{Data analysis.}

Eye movements were analyzed on a (video) frame by frame basis. Only samples from fixations were included in the analysis, because it can be assumed that visual information extraction takes place only during these intervals. Rectangular regions of interest were drawn around the head and body of the target actor for each frame of the video in which the actor was present (Figure 1). For each frame and each participant it was then determined whether the participant fixated the head, body or any other part of the screen. These numbers were then used to compute the percentage of frames in which the participant fixated the actor (from those frames in which the actor was present), the time (in ms) until first fixation of the actor (from the moment the actor appeared in the video), and the percentage of frames in which the participant fixated the actor's head rather than the body (from those frames in which the actor was fixated). During analysis of the data, it was discovered that for one of the video clips both groups of participants received a neutral statement (Video 17, see Table 4). This video was therefore excluded from the average data and overall data analysis. Questions at the end of each video clip served to keep participants engaged, and were not analyzed.

\section{Results}

Figure 2a compares eye movements towards the actor, the time to fixate the actor, and the time spent fixating the actor's head between participants who received the mental health information and those receiving the control advance information. Averages are shown separately for the two sets 
of videos used in counter-balancing, providing a direct (between subjects) comparison of identical videos (testing the unique effect of advance information). Results from independent samples t-tests, comparing the two types of advance information (mental illness and control), are shown as pvalues above the bars in the data plot (see also the first two data columns in Table 2). None of the comparisons showed an effect of advance information. Effect sizes (third data column in Table 2) ranged from 0.040 to 0.46 (Cohen's d), which denote small effects.

Videos varied in their contents and the severity of the mental health disorder attributed to the target actor. Studies have suggested that stigma differs across conditions (a strong stigma, for example, for schizophrenia). To examine whether there were videos (and therefore mental illnesses) for which group differences could be observed, Figure $2 \mathrm{~b}$ plots the difference between the two types of advance information separately for each of the videos. Positive values indicate that mental health information led to more time spent fixating the actor, quicker fixations on the actor, or more time spent fixating on the actor's head. Also here, none of the comparisons reached statistical significance (all p-values $<0.077$ ), and revealed no consistent results.

A subsequent, linear mixed effects model for split plot designs (Baayen, Davidson, \& Bates, 2008) pooled the random effects of participants and videos in a single analysis. Assuming random intercepts and slopes (Barr, Levy, Scheepers, $\&$ Tily, 2013), no effects of advance information on the percentage of actor fixations $\left(\chi^{2}(3)=0.70, p=0.87\right)$, the time until fixating the actor $\left(\chi^{2}(3)=2.99, \mathrm{p}=0.39\right)$, and the percentage of time spent looking at the actor's face $\left(\chi^{2}(3)=1.20, \mathrm{p}=0.75\right)$ were found.

Bayes factors (BF10 values; fourth data column in Table 2) were computed (using JASP, version 0.7.5.6) yielding values between 0.33 (percentage of face fixations for video set 1) and 0.79 (percentage of face fixations for video set 2), suggesting that while the data more strongly favor the null hypothesis than the alternative hypothesis, no strong evidence for the null hypothesis is obtained either (BF10's all larger than 0.30, but smaller than 1).

Data from the questionnaire are shown in Table 1, suggesting that depression and anxiety were considered to be more acceptable, while personality disorders, schizophrenia and post-traumatic stress disorders disorders were less often accepted. The responses to the individual questions were condensed into a single number for each participant by computing a weighted sum with weights based on the proportion of participants accepting a certain mental illness - profession combination. When the resulting scores for each participant were correlated with the various eye movement measures (Figure 2c), no evidence for significant associations was found (correlations and $\mathrm{p}$-values in the figure titles).

\section{Discussion}

Experiment 1 investigated whether social stigma associated with mental health conditions influences observers' eye movements to the individual involved. Participants viewed short video clips for which advance information about one of the actors was presented that was either stigmatizing, or did not stigmatize. No significant effects of the stigmatizing information on the eye movements were found, with associated small effect sizes, and inconsistent results across the trials. Eye movements did not correlate with attitudes towards mental health conditions as measured with a questionnaire. The results therefore suggest that advance information about a person's mental illness does not alter eye movements towards this person in a systematic way. Bayes factors did not provide sufficient evidence to strongly support the null hypothesis of no influence either, but given the small effect sizes and the inconsistency of the effects across trials, a pursuit towards more evidence in favor of the null hypothesis by increasing the sample size is unlikely to be fruitful (Johnson, 1999). Instead, a new set of statements and a new set of videos, now related to a different stigma (a criminal record), is tested in Experiment 2 on a new group of participants.

\section{Experiment 2}

Experiment 2 tests the effects of advance information about a person's criminal record on eye movements, and compares these to attitudes towards prisoners, measured using the attitudes towards prisoners scale (Melvin et al., 1985).

\section{Methods}

Participants.

Forty new participants (all students at the University of Lincoln, 32 females, between 18 and 25 years of age, $\mathrm{M}=20.6, \mathrm{SD}=1.42$ ) took part in the study in return for course credit or candy. Participants were recruited via an online system and word of mouth. All provided written consent for the study that was approved by the local ethics committee.

Apparatus, Design and Procedure. The same equipment, design and procedure was used as in Experiment 1.

Stimuli. Twelve short video clips (between 10 and $20 \mathrm{sec}-$ onds long) were created from material from Youtube depicting day-to-day events (for an overview, see Table 5). For each video clip, an image of one of the actors was extracted that was shown together with advance information (either stigmatizing or non-stigmatizing) before the presentation of the video clip (see Figure 1). After the having seen all the video clips, participants completed the attitudes towards prisoners scale (Melvin et al., 1985), presented on the same computer, while randomizing the order of the questions for each participant.

\section{Results}

Figure 3 and Table 3 provide the results of Experiment 2. $\mathrm{P}$-values in Figure 3a show the results of independent samples t-tests, showing that (after Bonferroni correction) no significant influence of advance information on eye movements is found. Plotted for each video separately (Figure 3b), no systematic effects of advance information on eye movements is found. Moreover, a mixed effects analysis (with random 


\section{a) Fixation averages}

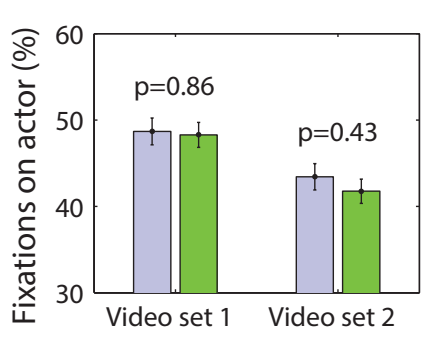

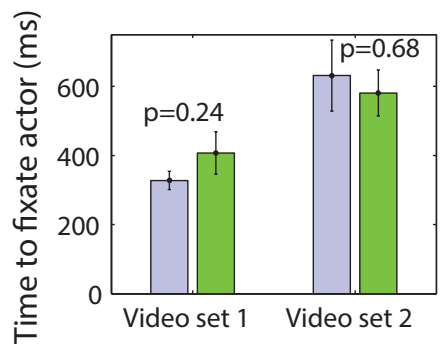

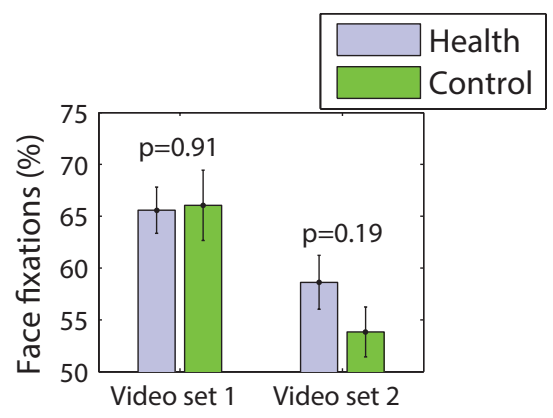

\section{b) Mental health effect per video}
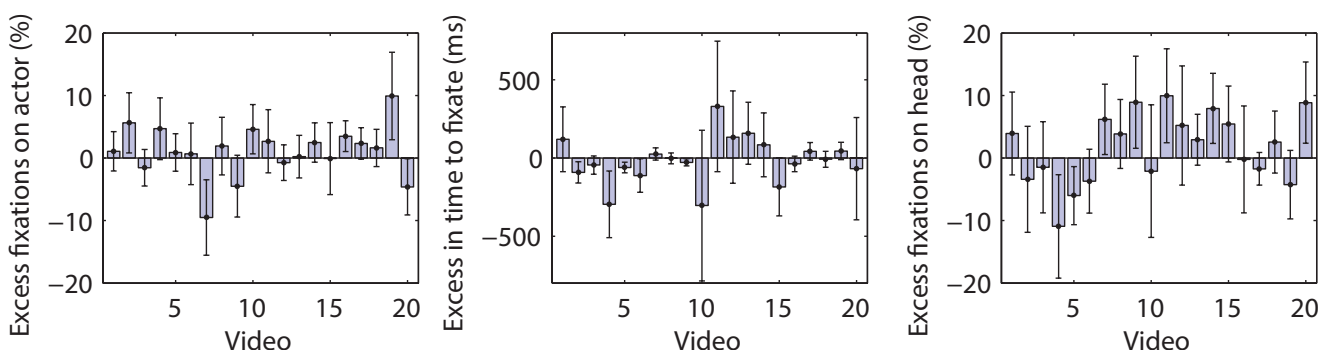

\section{c) Correlation with explicit attitude scores}
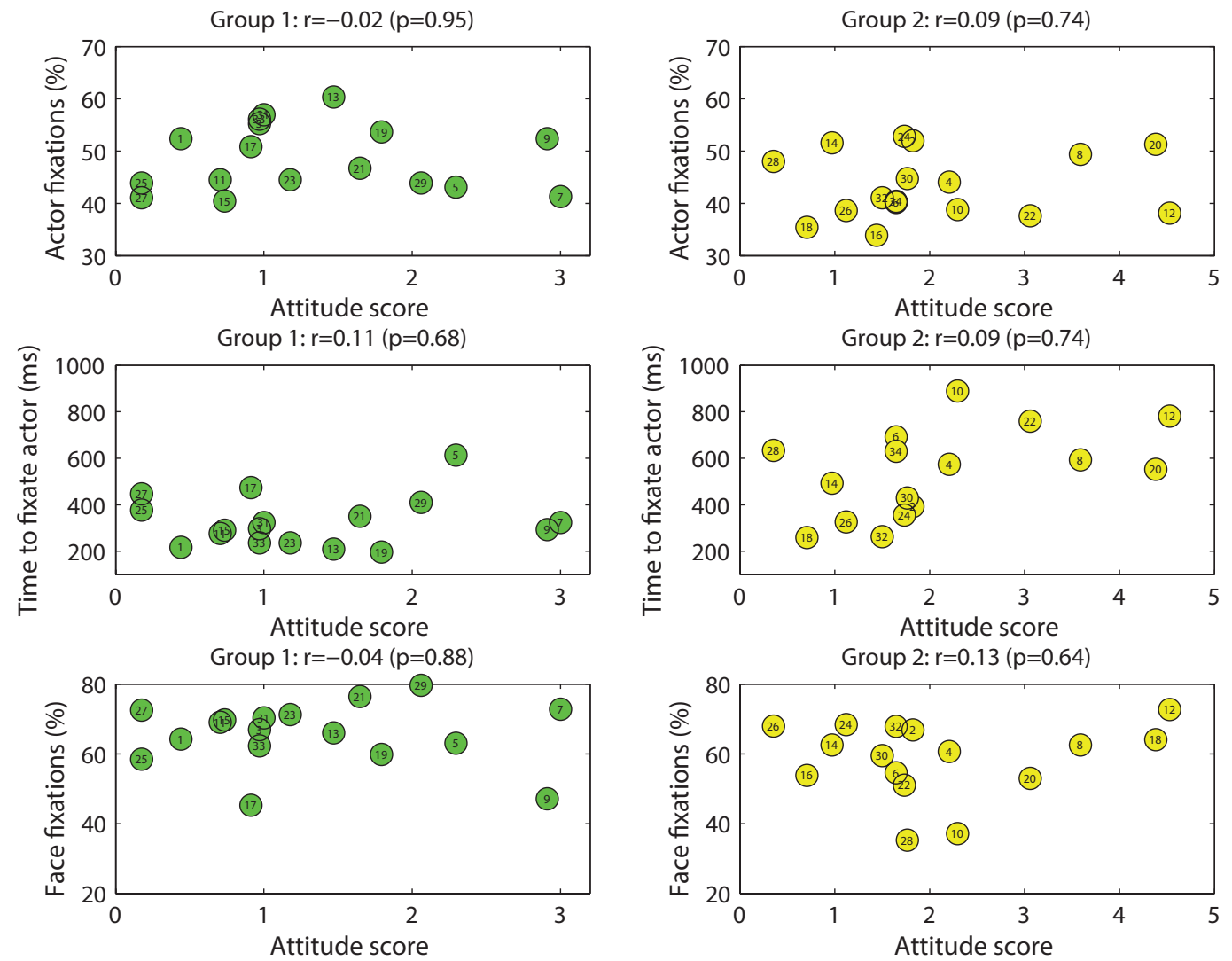

Figure 2. Results of Experiment 1, testing the effect of advance information on mental illness on eye movements. Different bars show half of the trials, so that comparisons between bars show a between-subjects comparison. a) Percentage actor fixations, time to fixate the actor, and percentage face fixations for the groups that received advance mental health information about the actor or neutral information, shown for the two sets of videos in the study. b) Differences in actor fixations, time to fixate the actor, and face fixations (positive values indicate higher values for mental illness information) for each of the video clips. c) Correlations between the different eye movement measures (rows) and the attitude scores derived from the questionnaire data (columns). 
Table 2

T-values, p-values, Cohen's d, and Bayes Factors (BF10) for the different comparisons in Experiment 1.

\begin{tabular}{llll}
\hline Comparison & t-value & p-value & Cohen's d \\
Actor fixations, Video set 1 & 0.18 & 0.86 & 0.063 \\
Actor fixations, Video set 2 & -0.80 & 0.43 & 0.27 \\
Time to fixate, Video set 1 & -1.19 & 0.24 & 0.41 \\
Time to fixate, Video set 2 & -0.41 & 0.68 & 0.33 \\
Face fixations, Video set 1 & -0.12 & 0.91 & 0.42 \\
Face fixations, Video set 2 & -1.33 & 0.19 & 0.040 \\
\hline
\end{tabular}

slopes and intercepts for items and participants), provides no evidence for an effect of advance information on the percentage of actor fixations $\left(\chi^{2}(3)=0.59, \mathrm{p}=0.90\right)$, time to fixate the actor $\left(\chi^{2}(3)=0.74, \mathrm{p}=0.86\right)$, or percentage face fixations $\left(\chi^{2}(3)=0.51, \mathrm{p}=0.92\right)$. Bayes factors range from 0.31 to 1.96 , which does provide strong evidence in favor of the null hypothesis or the alternative hypothesis. Effect sizes were generally small (Cohen's d of 0.29 or less), with one exception (actor fixations, set $2, \mathrm{~d}=-0.69$, a medium effect size). Finally, no significant correlations were found between the eye movement parameters and the explicit attitudes towards prisoners (ATP scores). The observed ATP scores were in the expected range (between around 45 and 130; similar to the range found for college students by Kjelsberg et al., 2007).

\section{General discussion}

Social stigmas associated with body features, such as scars, cleft lips and tattoos have been shown to attract observers' eye gaze (Madera \& Hebl, 2012; Meyer-Marcotty et al., 2010; Van Schijndel et al., 2015; Wohlrab et al., 2007). The present study examined whether this attraction of observers' gaze towards stigmatized individuals extends to social stigmas that may not have clearly visible features. In two experiments, eye movement patterns towards actors in video clips were measured to examine whether advance information about mental illness (Experiment 1) or criminal offenses (Experiment 2) in these actors influenced visual attention to these actors. Examination of overall time spent looking at the actor, time to first fixation and relative focus on the head region did not reveal systematic effects of social stigma. Furthermore, the various eye movement measures were unrelated to explicit attitudes towards the social stigmas as measured with questionnaires. The results therefore suggest that attraction of eye movements towards social stigma only occurs for stigmas that have visible cues.

Compared to previous studies on eye movements in social stigma (Madera \& Hebl, 2012; Meyer-Marcotty et al., 2010; Van Schijndel et al., 2015; Wohlrab et al., 2007), the present experiments used relatively small sample sizes (in particular in comparison with Madera \& Hebl, 2012, who tested 171 participants). Such a sample size as in Madera and Hebl (2012), however, is exceptional in eye tracking research, because participants need to be tested individually, eye tracking requires experience from the experimenter to obtain high quality data, and data analysis requires more effort than for, for example, questionnaire data or reaction times. To determine whether the lack of significant effects in the present study was due to the smaller sample sizes, a range of mea- sures and indicators was used. If stigma in the present context has small, but systematic effects on the observer, similar results were to be expected across video clips, eye movement measures (overall dwell time, time to first fixation, and face fixations), and the type of information given (mental illness or criminal history). No such systematic effects were found, and effect sizes were generally small, therefore suggesting that the absence of significant effects was not due to the smaller sample size. Stated differently, the small size of and lack of consistency in the effects make attempts to find conclusive evidence $(\mathrm{BF} 10>3.0$ or $<0.33)$ either in favor or against the null hypothesis a quest of limited interest. The data also suggest that eye movements are unlikely to play a role in detecting implicit biases in attitudes towards mental illnesses or a criminal past.

The question arises why the present study did not reveal systematic influences of mental health and offender history information on other people's eye movements, while past studies revealed influences of other stigmas such as scars, tattoos and cleft lips (Madera \& Hebl, 2012; Meyer-Marcotty et al., 2010; Van Schijndel et al., 2015; Wohlrab et al., 2007). A first possible reason is that these other stigmas change the visual properties of the stimulus, possibly increasing their visual salience (Itti, Koch, \& Niebur, 1998; Itti \& Koch, 2000, 2001). Scars, tattoos and clef lips change the bottom-up signals, while the presently investigated social stigmas relied on changes in top-down information only. A second difference that may have influenced the results is the type of stimulus used for eye tracking (images versus video clips). The present study used video clips, as these are more ecologically valid than still images, but motion is known to capture the eyes(Ludwig, Ranson, \& Gilchrist, 2008). Past studies, however, have been able to influence eye movements in video clips, by removing or adding a soundtrack (Coutrot, Guyader, Ionescu, \& Caplier, 2012), or by changing the videos from color to black and white (Hamel, Houzet, Pellerin, \& Guyader, 2015) and top-down influences of surgical expertise have been found on movements when watching videos of surgery (Khan et al., 2012).

Another possible factor could be the questions asked after the video clips, which served to keep participants engaged with the materials and to draw attention away from the actual purpose of the study. Past work, however, did not find systematic differences between eye movements of participants knowing that their memory for a scene would be probed and those instructed to simply look at the scenes (Hermens \& Walker, 2016, in press). Moreover, the present Experiment 2 used questions that were easier to answer than Experiment 1, with no clear effects on the results. It may have been the case 


\section{a) Fixation averages}
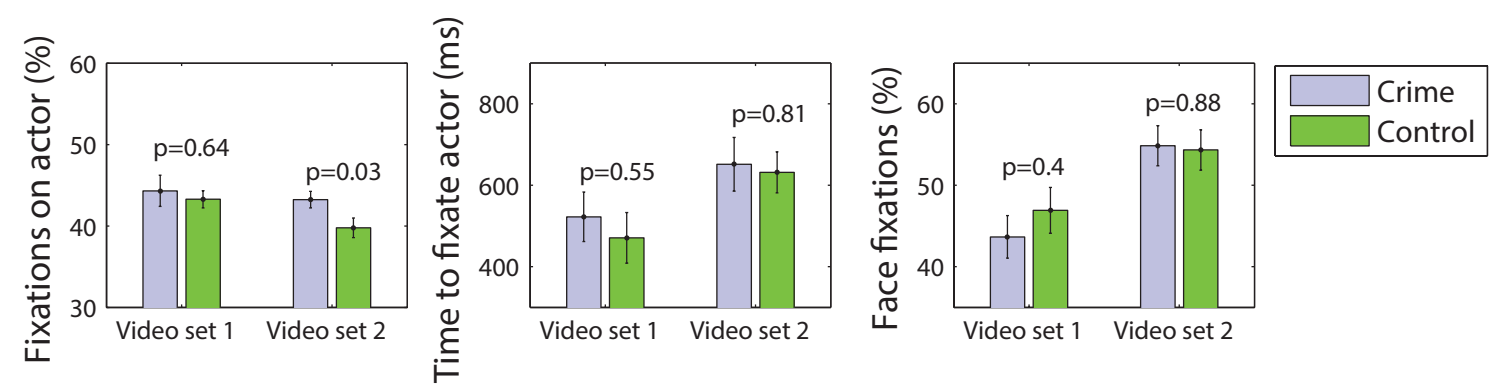

\section{b) Prisoner information effect per video}
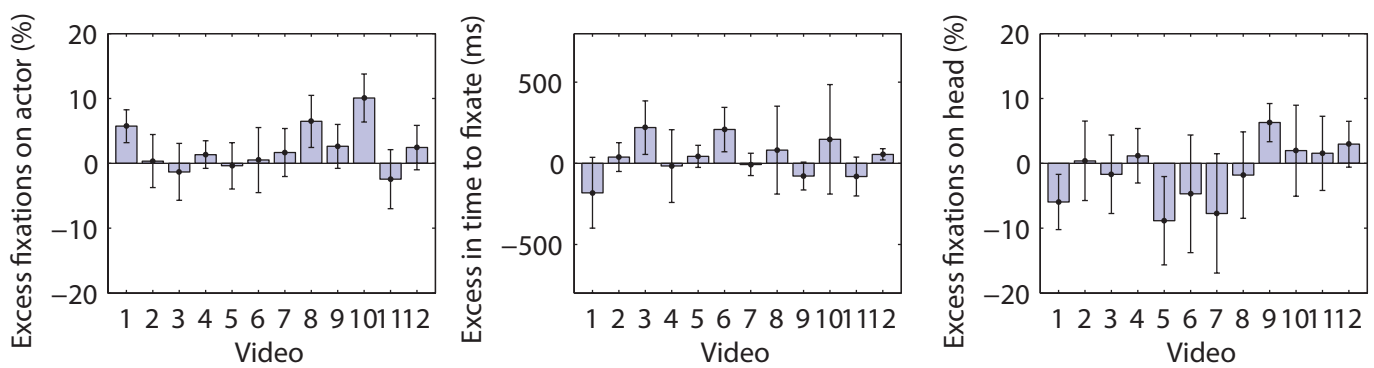

\section{c) Correlation with explicit attitude scores}
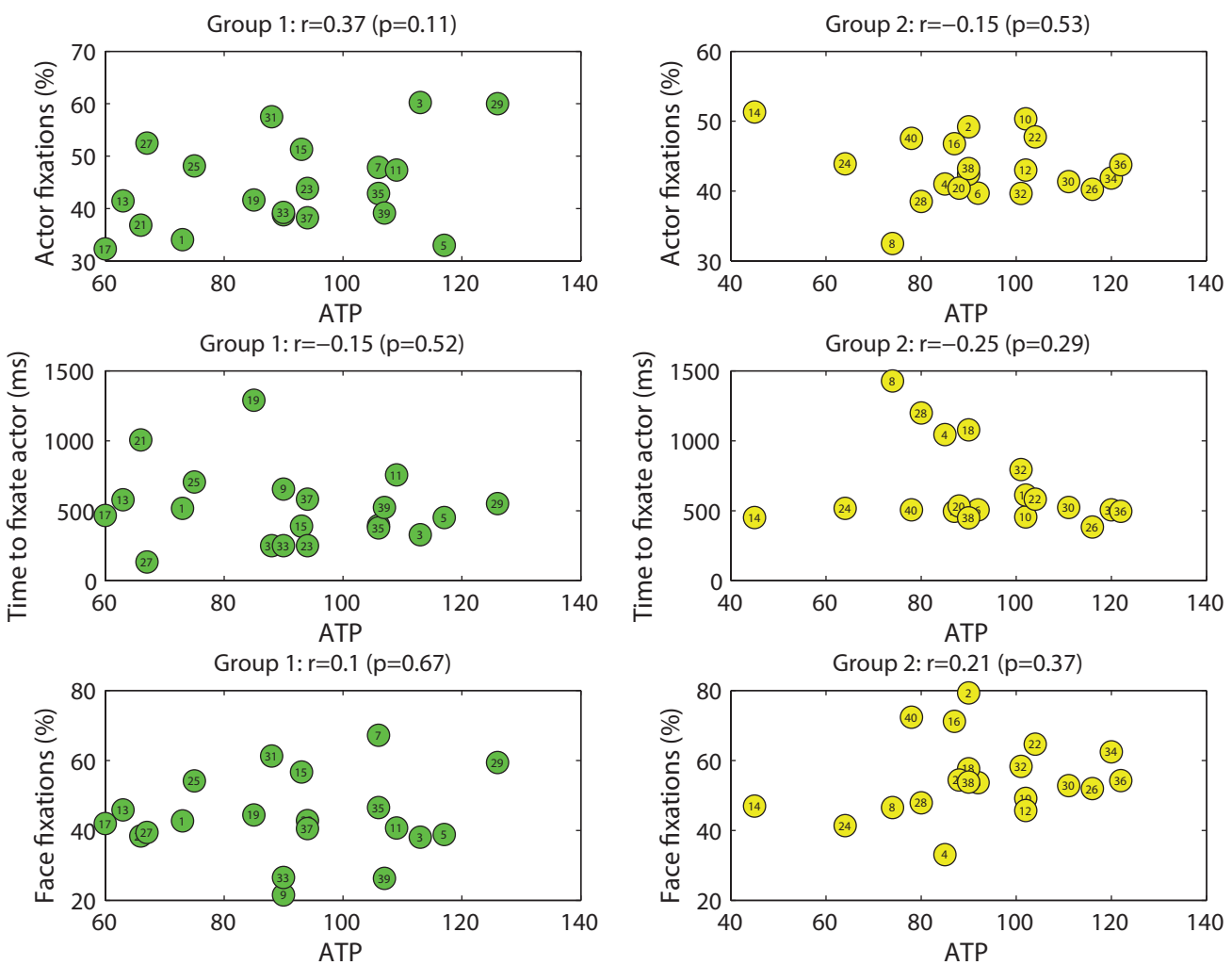

Figure 3. Results of Experiment 2, testing the effect of advance information about a criminal record on eye movements. Different bars present data from half of the trials, so that comparisons between bars reflect a between subjects comparison. a) Percentage actor fixations, time to fixate the actor, and percentage face fixations for the groups that received advance criminal record information about the actor or neutral information, shown for the two sets of videos in the study. b) Differences in actor fixations, time to fixate the actor, and face fixations (positive values indicate higher values for advance criminal history information) for each of the video clips. c) Correlations between the different eye movement measures (in rows) and the attitudes towards prisoners (ATP) scores (in columns). 
Table 3

T-values, p-values, Cohen's d, and Bayes Factors (BF10) for the different comparisons in Experiment 2.

\begin{tabular}{llll}
\hline Comparison & t-value & p-value & Cohen's d \\
Actor fixations, Video set 1 & 0.47 & 0.64 & 0.15 \\
Actor fixations, Video set 2 & -2.19 & 0.035 & -0.69 \\
Time to fixate, Video set 1 & 0.60 & 0.55 & 0.19 \\
Time to fixate, Video set 2 & -0.24 & 0.81 & -0.075 \\
Face fixations, Video set 1 & -0.85 & 0.40 & 0.34 \\
Face fixations, Video set 2 & -0.15 & 0.88 & -0.27 \\
\hline
\end{tabular}

that participants did not strongly believe the advance information. Asking participants at the end of the study, however, did not reveal that they questioned the information given. Finally, participants, being aware of that eye movements were recorded, may have changed their eye movements (Risko \& Kingstone, 2011). However, it is unclear why this would have affected the stigma and non-stigma conditions in different ways. Moreover, while observers can consciously control their eye movements, they tend to remember poorly where they looked (Clarke, Mahon, Irvine, \& Hunt, in press; Foulsham \& Kingstone, 2013).

\section{Conclusion}

In two experiments, the influence of advance stigmatizing information on observers' eye movements was investigated. In contrast to studies that examined stigmas with clear visual cues, such as scars, clef lips, and tattoos, no systematics influences of the stigmatizing information were found. For people with a mental illness and a criminal record the results may provide reassurance: Revealing this information does not change the way other people look at you.

\section{Appendix: Stimulus descriptions \\ References}

Baayen, R. H., Davidson, D. J., \& Bates, D. M. (2008). Mixedeffects modeling with crossed random effects for subjects and items. Journal of Memory and Language, 59(4), 390-412.

Barney, L. J., Griffiths, K. M., Jorm, A. F., \& Christensen, H. (2006). Stigma about depression and its impact on help-seeking intentions. Australian and New Zealand Journal of Psychiatry, 40(1), 51-54.

Barr, D. J., Levy, R., Scheepers, C., \& Tily, H. J. (2013). Random effects structure for confirmatory hypothesis testing: Keep it maximal. Journal of Memory and Language, 68(3), 255-278.

Clarke, A., Mahon, A., Irvine, A., \& Hunt, A. (in press). People are unable to recognize or report on their own eye movements. Quarterly Journal of Experimental Psychology.

Conner, K. O., Copeland, V. C., Grote, N. K., Koeske, G., Rosen, D., Reynolds, C. F., \& Brown, C. (2010). Mental health treatment seeking among older adults with depression: the impact of stigma and race. The American Journal of Geriatric Psychiatry, 18(6), 531-543.

Coutrot, A., Guyader, N., Ionescu, G., \& Caplier, A. (2012). Influence of soundtrack on eye movements during video exploration. Journal of Eye Movement Research, 5(4), 2.

De Houwer, J. (2002). The implicit association test as a tool for studying dysfunctional associations in psychopathology:
Strengths and limitations. Journal of Behavior Therapy and Experimental Psychiatry, 33(2), 115-133.

Driscoll, C., Heary, C., Hennessy, E., \& McKeague, L. (2012). Explicit and implicit stigma towards peers with mental health problems in childhood and adolescence. Journal of Child Psychology and Psychiatry, 53(10), 1054-1062.

Eisenberg, D., Downs, M. F., Golberstein, E., \& Zivin, K. (2009). Stigma and help seeking for mental health among college students. Medical Care Research and Review, 66(5), 522-541.

Fiedler, K., Messner, C., \& Bluemke, M. (2006). Unresolved problems with the $\mathrm{i}$, the a, and the t: A logical and psychometric critique of the implicit association test (iat). European Review of Social Psychology, 17(1), 74-147.

Foulsham, T., \& Kingstone, A. (2013). Where have eye been? observers can recognise their own fixations. Perception, 42, 10851089.

Gerdes, A. B., Pauli, P., \& Alpers, G. W. (2009). Toward and away from spiders: Eye-movements in spider-fearful participants. Journal of Neural Transmission, 116(6), 725-733.

Greenwald, A. G., McGhee, D. E., \& Schwartz, J. L. (1998). Measuring individual differences in implicit cognition: the implicit association test. Journal of Personality and Social Psychology, 74(6), 1464.

Hamel, S., Houzet, D., Pellerin, D., \& Guyader, N. (2015). Does color influence eye movements while exploring videos? Journal of Eye Movement Research, 8(1).

Hebert, J. R., Clemow, L., Pbert, L., Ockene, I. S., \& Ockene, J. K. (1995). Social desirability bias in dietary self-report may compromise the validity of dietary intake measures. International Journal of Epidemiology, 24(2), 389-398.

Hermens, F., \& Walker, R. (2016, in press). The influence of social and symbolic cues on observers' gaze behaviour. British Journal of Psychology.

Itti, L., \& Koch, C. (2000). A saliency-based search mechanism for overt and covert shifts of visual attention. Vision Research, 40(10), 1489-1506.

Itti, L., \& Koch, C. (2001). Computational modelling of visual attention. Nature Reviews Neuroscience, 2(3), 194-203.

Itti, L., Koch, C., \& Niebur, E. (1998). A model of saliency-based visual attention for rapid scene analysis. IEEE Transactions on Pattern Analysis \& Machine Intelligence(11), 1254-1259.

Johnson, D. H. (1999). The insignificance of statistical significance testing. The Journal of Wildlife Management, 763-772.

Khan, R. S., Tien, G., Atkins, M. S., Zheng, B., Panton, O. N., \& Meneghetti, A. T. (2012). Analysis of eye gaze: Do novice surgeons look at the same location as expert surgeons during a laparoscopic operation? Surgical Endoscopy, 26(12), 35363540.

Kjelsberg, E., Skoglund, T. H., \& Rustad, A.-B. (2007). Attitudes towards prisoners, as reported by prison inmates, prison employees and college students. BMC Public Health, 7(1), 1. 
Table 4

Videos and advance information in Experiment 1. The type of information was counter-balanced across participants, and participants received stigmatizing information in half of the trials. The statements were made up by the experimenters and did not relate in any way to the actors of the videos, but this was only revealed to the participants after the experiment.

\begin{tabular}{|c|c|c|}
\hline$\overline{\text { Video }}$ & Description & Advance information \\
\hline Video 1 & Police chasing a car & $\begin{array}{l}\text { N: The policeman in the following scene is out and about on everyday duties, looking after the community and catching } \\
\text { criminals. } \\
\text { S: The policeman in the following scene has been suffering from the mental illness schizophrenia for } 5 \text { years }\end{array}$ \\
\hline Video 2 & Elementary school scene & $\begin{array}{l}\mathrm{N} \text { : The teacher in the following scene is teaching maths to a class of children. This is their second day of understanding } \\
\text { the number-line. } \\
\text { S: The teacher in the following scene has been suffering from the mental illness depression for } 2 \text { years. }\end{array}$ \\
\hline Video 3 & Netball match & $\begin{array}{l}\mathrm{N} \text { : The netball player in the following scene is a committed team player and is prepared to win the commencing game. } \\
\mathrm{S} \text { : The netball player in the following scene has been suffering from the mental health disorder bipolar for } 4 \text { years. }\end{array}$ \\
\hline Video 4 & Wedding scene & $\begin{array}{l}\mathrm{N} \text { : The bride in the following scene is to get married to the man she wishes to spend the rest of her life with. } \\
\text { S: The bride in the following scene has been suffering from an anxiety disorder for three months. }\end{array}$ \\
\hline Video 5 & Models walking on a & $\mathrm{N}$ : The model in the following scene is promoting the new season's fashion. \\
\hline Video 6 & $\begin{array}{l}\text { Checkout assistant } \\
\text { scanning items }\end{array}$ & $\begin{array}{l}\text { S: The model in the following scene has been suffering from an eating disorder for most of her modeling career. } \\
\mathrm{N} \text { : The checkout assistant in the following scene has worked in the same supermarket for many years and thoroughly } \\
\text { enjoys her job. } \\
\text { S: The checkout assistant in the following scene has suffered from a personality disorder for } 7 \text { years. }\end{array}$ \\
\hline Video 7 & $\begin{array}{l}\text { Couple talking over } \\
\text { dinner }\end{array}$ & $\begin{array}{l}\mathrm{N} \text { : The lady in the following scene is on her first blind date with someone she met on an online dating website. } \\
\text { S: The lady in the following scene has suffered from paranoia from a young age. }\end{array}$ \\
\hline Video 8 & Postman delivering mail & $\begin{array}{l}\mathrm{N} \text { : The postman in the following scene is going about his normal day and delivering post to a local area. } \\
\text { S: The postman in the following scene was suffering from a post-traumatic stress disorder. }\end{array}$ \\
\hline Video 9 & $\begin{array}{l}\text { People brushing their } \\
\text { teeth }\end{array}$ & $\begin{array}{l}\mathrm{N} \text { : The lady in the following scene is going about her normal everyday routine and brushing her teeth. } \\
\mathrm{S} \text { : The lady in the following video has been suffering from schizophrenia for } 4 \text { years but is not on medication for the } \\
\text { mental health disorder. }\end{array}$ \\
\hline Video 10 & $\begin{array}{l}\text { Family sitting around a } \\
\text { table and having food }\end{array}$ & $\begin{array}{l}\mathrm{N} \text { : The man in the following scene is eating breakfast with his family. } \\
\mathrm{S} \text { : The man in the following scene has been suffering from self-harm for a couple of months. }\end{array}$ \\
\hline Video 11 & $\begin{array}{l}\text { Dentist performing a } \\
\text { routine check-up }\end{array}$ & $\begin{array}{l}\mathrm{N} \text { : The dentist in the following scene is preparing to begin a general check-up. } \\
\mathrm{S} \text { : The dentist in the following scene has been suffering from depression but is now on medication for this mental health } \\
\text { disorder. }\end{array}$ \\
\hline Video 12 & Hairdressing scene & $\begin{array}{l}\text { N: The hairdresser in the following scene has been in the profession for a few years and thoroughly enjoys her job. } \\
\text { S: The hairdresser in the following scene has suffered with hallucinations for } 10 \text { years. }\end{array}$ \\
\hline Video 13 & $\begin{array}{l}\text { Lady walking several } \\
\text { dogs }\end{array}$ & $\begin{array}{l}\mathrm{N} \text { : The lady in the following scene owns her own dog walking business. } \\
\mathrm{S} \text { : The lady in the following scene has suffered from self-harm for } 5 \text { years but is now being treated for this mental health } \\
\text { disorder. }\end{array}$ \\
\hline Video 14 & $\begin{array}{l}\text { Thanksgiving dinner } \\
\text { scene }\end{array}$ & $\begin{array}{l}\mathrm{N} \text { : The man in the following scene is celebrating thanksgiving with his family. } \\
\mathrm{S} \text { : The man in the following scene suffered from bipolar disorder for } 5 \text { years, but is now on medication for his mental } \\
\text { health illness. }\end{array}$ \\
\hline Video 15 & Gardening scene & $\begin{array}{l}\mathrm{N} \text { : The man in the following scene enjoys gardening in his spare time and is plant a new plant bed. } \\
\text { S: The man in the following scene has suffered from an anxiety disorder for } 7 \text { years, but is now being treated for his } \\
\text { mental illness. }\end{array}$ \\
\hline Video 16 & Football training & $\begin{array}{l}\mathrm{N} \text { : The man in the following scene has been coaching the same football team for more than } 5 \text { years and is committed. } \\
\text { S: The man in the following scene has suffered from hallucinations for } 2 \text { years but is now being treated for this mental } \\
\text { health illness. }\end{array}$ \\
\hline Video 17 & $\begin{array}{l}\text { Bouncers in front of } \\
\text { night club talking }\end{array}$ & $\mathrm{N}$ : The man in the following scene has been working for the same nightclub, in the same town for a few years. \\
\hline Video 18 & Swimming pool scene & $\begin{array}{l}\mathrm{N} \text { : The man in the following scene lifeguards at his local swimming pool. } \\
\text { mental health illness. }\end{array}$ \\
\hline Video 19 & Cyclists in a park & $\begin{array}{l}\text { N: The man in the following scene enjoys an afternoon bike ride in Central park with his friends. } \\
\text { S: The man in the following scene has suffered from a personality disorder for } 2 \text { year, but is now being treated for his } \\
\text { mental health illness. }\end{array}$ \\
\hline Video 20 & Baby sitting scene & $\begin{array}{l}\text { N: The lady in the following scene is babysitting one of her regular client's child. } \\
\text { S: The lady in the following scene suffers from paranoia but is now on medication for this mental health illness. }\end{array}$ \\
\hline
\end{tabular}

Komiti, A., Judd, F., \& Jackson, H. (2006). The influence of stigma and attitudes on seeking help from a gp for mental health problems. Social Psychiatry and Psychiatric Epidemiology, 41(9), $738-745$.

Ludwig, C. J., Ranson, A., \& Gilchrist, I. D. (2008). Oculomotor capture by transient events: A comparison of abrupt onsets, offsets, motion, and flicker. Journal of Vision, 8(14), 11-11.

Madera, J. M., \& Hebl, M. R. (2012). Discrimination against facially stigmatized applicants in interviews: an eye-tracking and face-to-face investigation. Journal of Applied Psychology, 97(2), 317.
Melvin, K. B., Gramling, L. K., \& Gardner, W. M. (1985). A scale to measure attitudes toward prisoners. Criminal Justice and Behavior, 12(2), 241-253.

Meyer-Marcotty, P., Gerdes, A., Reuther, T., Stellzig-Eisenhauer, A., \& Alpers, G. (2010). Persons with cleft lip and palate are looked at differently. Journal of Dental Research, 89(4), 400404.

Miltner, W. H., Krieschel, S., Hecht, H., Trippe, R., \& Weiss, T. (2004). Eye movements and behavioral responses to threatening and nonthreatening stimuli during visual search in phobic and nonphobic subjects. Emotion, 4(4), 323. 
Table 5

Videos and advance information in Experiment 2. Participants either received non-stigmatizing (N) and stigmatizing (S) information about the actor, counter-balanced across participants.

\begin{tabular}{|c|c|c|}
\hline Video & Description & Advance information \\
\hline Video 1 & Outdoors basketball game & $\begin{array}{l}\text { N: The man with the blue shirt has spent the last two and a half years working on his career. } \\
\text { S: The man with the blue shirt has just served a two and a half years prison sentence for robbery. }\end{array}$ \\
\hline Video 2 & Outdoors dinner scene & $\begin{array}{l}\text { N: The woman in the red dress has just got back from traveling in Europe. } \\
\text { S: The woman in the red dress has just served an } 18 \text { months prison sentence for indecent exposure. }\end{array}$ \\
\hline Video 3 & Couple walking together & $\begin{array}{l}\mathrm{N} \text { : The man in this video has just spent the last four years being a single parent. } \\
\mathrm{S} \text { : The man in this video has just served a four years sentence for rape. }\end{array}$ \\
\hline Video 4 & Man eating at an Asian restaurant & $\begin{array}{l}\text { N: This man has just found out he going to be a dad. } \\
\text { S: This person has just received a two year suspended sentence for theft. }\end{array}$ \\
\hline Video 5 & Man dancing outside & $\begin{array}{l}\text { N: This man has recently become a parent. } \\
\text { S: This man has recently been charged with attempted murder. }\end{array}$ \\
\hline Video 6 & Man dancing on the street & $\begin{array}{l}\text { N: This man dancing in the video is newlywed. } \\
\mathrm{S} \text { : This man dancing in the video is a convicted pedophile. }\end{array}$ \\
\hline Video 7 & Football coach talking to team & $\begin{array}{l}\mathrm{N} \text { : This man has been happily married for the last ten years. } \\
\mathrm{S} \text { : This man has just served a ten years prison sentence for child abuse. }\end{array}$ \\
\hline Video 8 & Couple getting married & $\begin{array}{l}\text { N: The bride has recently found out she is pregnant. } \\
\text { S: The bride has recently been charged with child abduction. }\end{array}$ \\
\hline Video 9 & Couple dancing & $\begin{array}{l}\text { N: This woman has just got engaged. } \\
\text { S: This woman has recently appeared in court for manslaughter. }\end{array}$ \\
\hline Video 10 & Men in running competitions & $\begin{array}{l}\mathrm{N} \text { : This man has just proposed to his girlfriend. } \\
\mathrm{S} \text { : This man just got sentenced for fifteen years for murder. }\end{array}$ \\
\hline Video 11 & Men talking to each other & $\begin{array}{l}\text { N: This man owns his own business. } \\
\text { S: This man has been charged with fraud five times. }\end{array}$ \\
\hline Video 12 & Man looking at his phone in a train & $\begin{array}{l}\text { N: This man has just adopted a puppy. } \\
\text { S: This man is a convicted murderer. }\end{array}$ \\
\hline
\end{tabular}

Mortel, T. F. Van de, et al.. (2008). Faking it: social desirability response bias in self-report research. Australian Journal of Advanced Nursing, The, 25(4), 40.

Nadeem, E., Lange, J. M., Edge, D., Fongwa, M., Belin, T., \& Miranda, J. (2007). Does stigma keep poor young immigrant and us-born black and latina women from seeking mental health care? Psychiatric Services.

Nederhof, A. J. (1985). Methods of coping with social desirability bias: A review. European Journal of Social Psychology, 15(3), 263-280.

Nyström, M., Andersson, R., Holmqvist, K., \& Van De Weijer, J. (2013). The influence of calibration method and eye physiology on eyetracking data quality. Behavior Research Methods, 45(1), 272-288.

Pager, D. (2003). The mark of a criminal record1. American Journal of Sociology, 108(5), 937-975.

Reynders, A., Kerkhof, A., Molenberghs, G., \& Van Audenhove, C. (2014). Attitudes and stigma in relation to help-seeking intentions for psychological problems in low and high suicide rate regions. Social Psychiatry and Psychiatric Epidemiology, 49(2), 231-239.

Rinck, M., \& Becker, E. S. (2006). Spider fearful individuals attend to threat, then quickly avoid it: evidence from eye movements. Journal of Abnormal Psychology, 115(2), 231.

Risko, E. F., \& Kingstone, A. (2011). Eyes wide shut: implied social presence, eye tracking and attention. Attention, Perception, \& Psychophysics, 73(2), 291-296.

Schomerus, G., Matschinger, H., \& Angermeyer, M. C. (2009). The stigma of psychiatric treatment and help-seeking intentions for depression. European Archives of Psychiatry and Clinical Neuroscience, 259(5), 298-306.

Schwartz, R. D., \& Skolnick, J. H. (1962). Two studies of legal stigma. Social Problems, 10(2), 133-142.

Van Schijndel, O., Litschel, R., Maal, T. J., Bergé, S. J., \& Tasman, A.-J. (2015). Eye tracker based study: Perception of faces with a cleft lip and nose deformity. Journal of Cranio-Maxillofacial Surgery, 43(8), 1620-1625.
Wohlrab, S., Fink, B., Pyritz, L. W., Rahlfs, M., \& Kappeler, P. M. (2007). Visual attention to plain and ornamented human bodies: An eye-tracking study. Perceptual and Motor Skills, 104(3), 1337-1349. 